\section{Everybody, Refugees, Assembly and the West: The Power of Naming}

\section{OLIVIER ROZENBERG}

The performance of naming social phenomena is a distinctive, if not the distinctive, feature of politics. This Aristotelian view is often understood in a quasi-biblical sense according to which naming is the key step for giving existence to things and elements. In the contemporary democratic age, the linguistic aspect of the process of representation is also often pointed to. In practice, political representation supposes indeed to name the represented and the representatives. Yet, a more general political meaning of the naming process can also be suggested. Linguistic conflicts on how to name a given group or a phenomenon do not necessarily create these groups and phenomena. Arguably, they contribute first and foremost to frame the collective understanding of what is at stake. Actors' political strategies are therefore, in part, linguistic ones for imposing names, concepts and meanings. As other kinds of strategies, they may fail or win: the understanding of what is meant by a given word may or may not be challenged - as the degree of agreement on how to designate such group or such process.

The four contributions collected within this issue of Redescriptions offer a further illustration that the power of naming is a core aspect of politics. The notions of 'everybody', 'the people' and 'the elite' is central to populist discourses as pointed by the cinematic comparison of Anna Schober. For Magdalena Kmak, the subjectivity of the 'refugees', rooted in the history of political thought, could frame our understanding of contemporary migration issues. Onni Pekonen explores one century of hesitations over the very name of the Finnish parliament which resulted from deep political and geopolitical conflicts about democracy and sovereignty. One century later, West German parliamentary debates during the oil crisis of 1973 touched upon the conception of what 'the West' is as analysed by Ann-Judith Rabenschlag in the fourth contribution. In a context of division of Germany, the discussions around the notion of 'westernism' was a way of questioning the German identity. 'Everybody', refugees, assemblies' names and 'the West': the concepts discussed in this issue refer to unrelated cases. Yet, each one illustrates how politically crucial naming is and how politics is necessarily, at some stages, about words and wording.
EDITORIAL

\section{HUP Prang}

CORRESPONDING AUTHOR:

\section{Olivier Rozenberg}

Center for European Studies and Comparative Politics, Sciences Po, FR

olivier.rozenberg@sciencespo. fr

\section{KEYWORDS:}

concept; naming; everybody; refugees; assembly; west

\section{TO CITE THIS ARTICLE:} Rozenberg, Olivier. 2021. "Everybody, Refugees, Assembly and the West: The Power of Naming." Redescriptions: Political Thought, Conceptual History and Feminist Theory 24(2): 89-91. DOI: https://doi. org/10.33134/rds.365 
Anna Schober proposes an original comparison between an American and a recent French movie to analyse key features of the populist speech. Meet John Doe (1941) by Frank Capra offers a relevant example of the figure of the 'everybody' (through Gary Cooper's role) and its political seduction in the eyes of the public - a seduction based on the authenticity of the main character and, paradoxically, on his lack of charisma. The elaborated staging of the movie positions the viewers both as a possible victim of populism and as its critical analyst. This first movie finds a great echoes with one realised in France recently: Chez Nous (This is Our Land, Lucas Belvaux 2017). Similarly, an ordinary woman, originally remote from politics, attracts popular support given her style of ordinary woman. Contextual variations between the cases are to be noted yet given the attention for ethnic identity in contemporary Europe. The comparison points to the richness of cinema for enhancing key aspects of political phenomena, here populism. In that respect, speech-making appears to be closely connected to other aspects of personal staging, such as clothing and body language. This indicates that the politics of naming is necessarily embodied within specific contexts and belongs to a continuum with non-verbal elements.

Magdalena Kmak promotes a shift from legal discourses on refugees rooted in a victimization/securitization narrative towards a subjective law-based perspective. Such shift supposes to question a state-based conception of refugees, focussed on borders and order, and to consider mobility and its internal perceptions instead. The heart of the conceptual proposal lies in a willingness to consider seriously the refugees' subjective perceptions, especially in their legal dimension. The reflections of some German-Jewish scholars exiled in 1930s - Hannah Arendt, Louise Holborn and Otto Kirchheimer - provides meaningful contributions to this alternative conception. Crucially, the own experience of exile of these thinkers paved the way for the subjectivation of the notion. It indicates that analysts and writers cannot be separated from the politics of naming and that their own conceptualizations are inherently political.

Onni Pekonen proposes a rich historical account of the nineteenth-century debates on how the Finnish Parliament should be named. The hesitations and changes reflect two distinct logics: a geopolitical one given the influence of a variety of European States on Finland throughout the period and a more political one with the encapsulation of diverse conceptions of the nation and the people by alternative naming. The article shows that, in practice, both dimensions were mixed: transnational transfers of norms through specific naming are not separable from domestic rivalries for imposing names. The remarkable instability of the assembly title during one century indicates that there is nothing automatic in the process of stabilizing how central institutions are named. Such instability constitutes therefore a remarkable account of the lack of equilibrium of a given political situation.

Ann-Judith Rabenschlag also focusses on semantic struggles analysing how the notion of 'the West' was mobilised during debates within the Bundestag related to the oil crisis in 1973/1974. A diversity of narratives are associated with the concept of the West. The article demonstrates that among the salient ones, the civilizational aspects were not a matter of conflict when the political ones were controversial. The two main political forces did not frame it similarly indeed: cold war geopolitics dominated the conservative interpretations while the social-liberal majority troops focused on European integration. Beyond short-term political tactics, these different framings reflected domestic struggles on German identity. When talking about the Western world, conservative German MPs emphasized the necessity to restore strong ties with
Thought, Conceptual History and Feminist Theory

DOI: $10.33134 /$ rds. 365 
the United States when majority ones called for greater solidarity within Europe - a solidarity that was challenged by the unequal saliency of the oil crisis. The fact that it is possible to identify both agreements and disagreements around the same concepts among the main political forces lead to refine the classical view that parliamentary debates feed a pro e contra process consisting in systematically developing alternative claims on any topic. Within the 1973 Bundestag where neither the notion of 'the West' was challenged, nor the belonging of Germany to it, parliamentary debates were central to identify on which aspects political pluralism could still be expressed despite such large consensus. Talking in parliament, the privileged institutional route of the politics of naming, was therefore essential to balance cohesion and pluralism.

\section{COMPETING INTERESTS}

The author has no competing interests to declare.

\section{AUTHOR AFFILIATION}

\section{Olivier Rozenberg}

Center for European Studies and Comparative Politics, Sciences Po, FR
Rozenberg

Redescriptions: Political

Thought, Conceptual

History and Feminist

Theory

DOI: $10.33134 /$ rds. 365

TO CITE THIS ARTICLE: Rozenberg, Olivier. 2021. "Everybody, Refugees, Assembly and the West: The Power of Naming." Redescriptions: Political Thought, Conceptual History and Feminist Theory 24(2): 89-91. DOI: https:// doi.org/10.33134/rds.365

Submitted: 30 October 2021 Accepted: 30 October 2021 Published: 16 December 2021

\section{COPYRIGHT:}

(c) 2021 The Author(s). This is an open-access article distributed under the terms of the Creative Commons Attribution 4.0 International License (CC-BY 4.0), which permits unrestricted use, distribution, and reproduction in any medium, provided the original author and source are credited. See http:// creativecommons.org/ licenses/by/4.0/.

Redescriptions: Political Thought, Conceptual History and Feminist Theory is a peer-reviewed open access journal published by Helsinki University Press. 